\title{
Disponibilidade e Acessibilidade do Sistema de Avaliação Institucional do Centro Estadual de Educação Tecnológica Paula Souza sob a ótica de seus gestores
}

\author{
Availability and Accessibility of the Institutional Evaluation \\ System of the Institutional of the State Center of \\ Technological Education Paula Souza under managers' view
}

\author{
Rita Aparecida Souza da Luz ${ }^{1}$ \\ ${ }^{1}$ Centro Estadual de Educação Tecnológica Paula Souza | Unidade de Ensino Médio e \\ Técnico| São Paulo | SP | Brasil. Contato: ritaapluz@ gmail.com. ORCID: \\ http://orcid.org/0000-0002-9161-5427
}

\section{Leandro Petarnella ${ }^{2}$}

${ }^{2}$ Universidade Nove de Julho | Diretoria de Ciências Gerenciais | São Paulo | SP | Brasil.

Contato: leandro_66@hotmail.com. ORCID: http://orcid.org/0000-0001-5157-4969

\author{
Amelia Silveira ${ }^{3}$ \\ ${ }^{3}$ Universidade Federal de Santa Catarina | Programa de Pós-graduação em Administração | \\ Florianópolis | SC | Brasil. Contato: ameliasilveira@ gmail.com. ORCID: \\ http://orcid.org/0000-0002-0321-8174
}

Resumo: Avaliar os resultados obtidos por meio das ações institucionais do processo avaliativo, em um sistema formalmente constituído, apresenta-se como um desafio ainda maior considerando a questão que envolve a disponibilidade e a acessibilidade do sistema de avaliação. Neste sentido, o entendimento dos gestores sobre esses dois aspectos se firma como condição fundamental para o delineamento de ações voltadas para a melhoria dos processos avaliativos, sendo necessária a análise do respectivo entendimento. Esta análise, por sua vez, se constitui como o objetivo do presente trabalho. O caminho investigativo percorrido para o alcance do objetivo foi conduzido por uma pesquisa de caráter qualitativa, realizada por meio de técnicas de análise documental, observação participativa e grupo de foco. Os resultados evidenciaram que há entendimento quanto ao assunto, bem como acerca das questões que se relacionam à disponibilidade e a acessibilidade pelos gestores do SAI. Entretanto, seus resultados não alcançam toda comunidade acadêmica, já que o SAI disponibiliza e torna acessível o sistema apenas aos gestores e diretores das Etecs.

Palavras-chave: Avaliação Institucional. Disponibilidade. Acessibilidade. Sistema de Avaliação Institucional (SAI).

Abstract: Evaluating the results obtained through the institutional actions of the evaluation process, in a formally constituted system, itself an even greater challenge considering the issue that involves the availability and accessibility of the evaluation system. In this sense, the managers' understanding of these two aspects is established as a fundamental condition for the design of actions aimed at the improvement of the evaluation processes, and it is necessary to analyze the respective understanding. This analysis, in turn, constitutes the objective of this paper. The research path followed to reach the objective was conducted by a qualitative research, carried out through techniques of documentary analysis, participatory observation and focus group. The results showed that there is an agreement on the subject, as well as on the issues related to availability and accessibility by the SAI managers. However, its results do not reach the entire academic community, since the SAI makes the system available and accessible only to the managers and directors of the Etecs.

Keywords: Institutional Evaluation. Availability. Accessibility. System of Institutional Evaluation (SAI).

- Recebido em: 26 de setembro de 2018 • Aprovado em: 7 de março de 2020

DOI: http://dx.doi.org/10.1590/S1414-407720200001000012

Este é um artigo publicado em acesso aberto sob uma licença Creative Commons

https://creativecommons.org/licenses/by-nc/4.0/ 


\section{Introdução}

A palavra avaliação possui diversos significados, tais como: medir, comparar, analisar, dentre outros. Destaca-se o significado do termo avaliação em sentido estrito ou sistemático, o qual nos leva ao entendimento de que toda e qualquer atividade humana está sujeita a ser avaliada. Em decorrência disto, a avaliação se converte em processo que permite conhecer, aprimorar e orientar as ações dos indivíduos e das organizações sociais, tanto no que se refere ao que já foi realizado, quanto ao amparo para avaliar a tomada de decisões nas realizações presentes e futuras.

Concorda-se neste trabalho com Freitas e Silveira (1997, p. 22-29), que embora existam conceitos que envolvem a avaliação como um processo que visa à melhoria da qualidade do objeto avaliado, de forma geral, este não deve ser entendido como único. Isto porque, a avaliação se caracteriza como um caminho para o aperfeiçoamento e o desenvolvimento de ações que, orientadas por concepções, critérios e etapas previamente estabelecidas, possam ser consolidadas por meio de um plano. A partir deste entendimento, pode-se perceber então que quando alinhada aos processos educativos, a avaliação se mostra como um desafio a ser enfrentado, constituindo-se como um problema educacional quando vinculado à necessidade de se avaliar um sistema educativo.

Importa ressaltar que os desafios e os problemas avaliativos se alteram e se amalgamam a partir e dentro de cada tempo, no qual a educação opera. Logo, há de se concordar com Guba e Lincoln (1994), quando se referem à essa como uma proposta de negociação sempre em construção, cuja edificação possui, em seus princípios, professores, alunos e demais atores valendo-se, para tanto, de formas diversificadas para fazê-la. Considera-se, nesta lógica, a avaliação como meio de desenvolvimento das aprendizagens e não de julgamento ou classificação em escala. No sentido exposto, desvela-se o papel institucional como primordial para a mudança do processo de avaliação e do padrão avaliativo secularmente instituído.

Pelas razões apresentadas, avaliar os resultados obtidos por meio das ações institucionais do processo avaliativo em um sistema formalmente constituído, apresenta-se como um desafio ainda maior. E, aqui, ganha força o Sistema de Avaliação Institucional (SAI), criado pela Área de Avaliação Institucional do Centro de Estadual de Educação Tecnológica Paula - CEETEPS (CEETEPS, 2013).

O SAI do CEETEPS se firma como processo avaliativo voltado para um padrão de avaliação institucional que garanta a qualidade educacional, já que a busca pela qualidade se tornou um desafio a ser enfrentado por todos os níveis educacionais. Defrontando-se com este 
desafio, os conceitos de eficiência, eficácia e efetividade se firmam no ambiente educacional em meio a um cenário mundial, que se organiza em programas de qualidade e certificações.

Dentro do panorama apresentado, com o intuito de garantir a qualidade da educação, que desde o ano de 1997, o CEETEPS, denominado aqui simplesmente de Centro Paula Souza, volta-se para o processo de avaliação de suas unidades educacionais de ensino. Desde então, o processo avaliativo evoluiu e se firmou, sendo concretizado, atualmente, por meio de seu Sistema de Avaliação Institucional, denominado SAI.

O SAI tem por objetivo avaliar anualmente o desempenho das Escolas Técnicas Estaduais (Etecs). Por meio de mecanismos que coletam informações junto à comunidade acadêmica, juntamente com pais de alunos e egressos, avalia os processos de funcionamento das Unidades de Ensino, seus resultados e o impacto na realidade social na qual se encontram inseridas. De forma específica, as Escolas Técnicas Estaduais (Etecs) e as Faculdades de Tecnologia do Estado de São Paulo (Fatecs) integram o Centro Paula Souza. Vale ressaltar que os cursos técnicos incluem habilitações na modalidade semipresencial, Educação de Jovens e Adultos (EJA) e especialização técnica. Quanto à avaliação, anualmente até 2012 foram avaliados em seu sistema os seguintes aspectos: processo, produto e benefício.

A partir de 2013, com a reformulação do SAI, foram consideradas as avaliações sob os aspectos de insumo, processo e aspectos que se transformam em resultados tangíveis à comunidade escolar. Esses são dependentes de uma série de fatores de ordem, inclusive, cultural, já que o Centro possui unidades espalhadas por todo Estado de São Paulo (CEETPS, 2015).

Considerando este contexto dinâmico e entendendo que as avaliações institucionais devem estar disponíveis e acessíveis a todos os participantes do cenário educacional, observase a importância da disponibilidade e a acessibilidade do respectivo sistema de avaliação. Assim, tratando-se de um sistema de informação, a disponibilidade deve ser entendida como uma medida da prontidão do sistema e, sob este aspecto, a acessibilidade como perspectiva de realizar o uso desta informação de fato, ou seja, estar acessível plenamente.

Sob este viés, os autores que melhor sustentam o entendimento sobre disponibilidade e acessibilidade, atributos de qualidade em sistemas de informação são: Brasil (2013); Lima (2003); Brasil (2004); Leporini; Paternò (2004); Henry (2005); Tanaka (2009); N'DONGA (2010); Piedade (2016) e Paula Filho (2016). Salienta-se, ainda, que há necessidade de que os gestores tenham o entendimento sobre a disponibilidade e a acessibilidade do SAI para melhor gerenciá-las, assegurando sua qualidade, o que justifica o interesse do presente trabalho. 
Poucos são os estudos sobre avaliação orientados para estes dois atributos: disponibilidade e acessibilidade, sobretudo com especificidade ao SAI do CEETPS.

Neste sentido, a análise realizada acerca dos elementos aqui apresentados torna permissível o avanço do próprio SAI, bem como o alcance de resultados esperados pelo referido Centro educacional. Para tanto, estabeleceu-se como eixo direcionador do caminho investigativo uma questão de pesquisa que se volta para a disponibilidade e a acessibilidade do Sistema de Avaliação Institucional do Centro Paula Souza, com especificidade ao entendimento sobre até que ponto os gestores levam este assunto e consideração.

A organicidade do presente artigo se constitui com o objetivo de analisar o entendimento dos gestores do SAI sobre a disponibilidade e a acessibilidade do Sistema, já que este tema se apresenta como um desafio e, ao mesmo tempo, como possibilidade de melhorias futuras do próprio sistema.

Para o cumprimento do referido desafio, traçou-se aqui um caminho investigativo que se inicia com esta introdução. Posteriormente, fundamenta-se sob a literatura acerca do tema e dos documentos legais. A análise dos discursos dos gestores é apresentada após a descrição metodológica para serem discutidas na seção dos resultados que, por sua vez, permitiram o encaminhamento deste às vias de conclusão.

\section{Avaliação Institucional}

As discussões sobre a Avaliação Institucional não são recentes. Ristoff (1995) afirma que essas iniciaram desde 1982 e ressalta que as instituições teriam que ter consciência da necessidade de garantir a qualidade do ensino, da pesquisa e da extensão para sobreviver. Este entendimento implica em visualizar a avaliação sob as égides política, acadêmica e administrativa, sem aventar a possibilidade de que isto possa ocorrer de forma uni ou bilateral. Argumenta-se, ainda, que se a qualidade do ensino não fosse garantida nestes broqueis, a mesma seria um fracasso (RISTOFF, 1995).

Ao longo destas três décadas, muitas reflexões e pesquisas foram desenvolvidas sobre esta temática. Essas, por sua vez, renovam-se a cada dilema imposto pela própria hodiernidade acadêmica como, por exemplo, as mudanças paradigmáticas, o avanço tecnológico e, até mesmo, a conduta dos indivíduos em sociedade. Desta maneira, a avaliação se firma e se mostra como um desafio sempre atual a ser encarado, cujo enfrentamento, em específico neste trabalho, dá-se por meio de duas premissas, quais sejam: a primeira, de maneira cronológica, que se torna possível evidenciar as transformações pelas quais os sistemas de avaliação têm passado ao 
longo dos anos; a segunda é de que os trabalhos desenvolvidos vão, com maior ou menor grau de profundidade, revelar os gargalos pelos quais o sistema de avaliação institucional ainda emperram.

Como resultado, as reflexões iniciais se voltam para o viés de que a avaliação institucional se destine à avaliação de políticas, de projetos e de instituições, pois a mesma deve ser concebida a partir da necessidade de se avaliar o desempenho das instituições escolares. A respeito das avaliações de desempenho institucional, com especificidade às instituições de ensino, Belloni (1969) aponta que o principal objetivo dessas é justamente criar, face aos seus objetivos ou missão, métricas capazes de atingir os resultados esperados. Para tanto, deve-se considerar os fatores sócios econômicos, políticos e culturais nas quais as instituições se inserem, avaliando também os processos de funcionamento e seus resultados (BELLONI, 1969).

Dias Sobrinho, em 2005, já alertava para a dificuldade de se estabelecer novos sentidos sobre as próprias transformações pelas quais a sociedade estava passando e, principalmente, para o estabelecimento de "novas visões dos novos papéis da educação superior, suas relações com a sociedade civil e com o Estado" (DIAS SOBRINHO, 2005, p. 6).

Para o autor, a qualidade, a acreditação e a garantia da qualidade, firmavam-se com a tríade constituinte do processo de avaliação, entendendo esta última como sinônimo do processo de melhoria (DIAS SOBRINHO, 2005). Salienta-se, que a avaliação institucional quando pensada como processo de melhoria pode contribuir com as metas estabelecidas na gestão universitária. Essas metas, apesar de se direcionarem por missões e valores que variam de instituição para instituição, partem, geralmente, de um eixo comum que o Sistema Nacional de Avaliação da Educação Superior - SINAES evoca com muita propriedade o estabelecimento de comissões que possam orientar um processo autoavaliativo.

Sobre o exposto, os trabalhos de Ashley et al. (2006) assevera que as referidas comissões podem e devem incorporar novos parâmetros ao sistema que sejam convergentes as necessidades de cada instituição. Neste sentido, pode-se, então, (re) aplicar as bases fundantes do SINAES em qualquer nível ou tipo de instituição que necessite de um sistema avaliativo adaptado à sua gestão. Mesmo porque, conforme explicita Silva e Gomes (2011), o SINAES atualmente é a base de informações que permite o delineamento da cultura de avaliação de instituições de ensino permitindo, desta maneira, a busca sistematizada pela melhoria contínua das instituições.

Avançando o pensar acerca dos processos avaliativos, Costa, Bara e Garcia (2013), ao analisar os resultados do Programa de Avaliação Institucional das Universidades Brasileiras 
(PAIUB), perceberam que as possibilidades de avanço e de melhoria contínua estão justamente na incorporação das "vivências" diversificadas dos agentes que compõem o cotidiano da instituição. Para os autores, esta incorporação permite adaptar o sistema avaliativo à realidade da instituição.

A este respeito, Andriola e Souza (2010), apontam para o fato de que a representação de cada um e, ao mesmo tempo, de todos os segmentos no processo de elaboração do sistema autoavaliativo é condição sine qua non para o sucesso almejado.

Aqui percebe-se que a tratativa sobre as avaliações institucionais tem avançado. Entretanto, visualiza-se, também, que o cerne do debate ainda se concentra sobre como alcançar a qualidade, a acreditação e garantir a qualidade do sistema como exposto por Dias Sobrinho em 2005. Contudo, mais recentemente, Terçariol et al. (2016) concluíram que é justamente a avaliação constante dos sistemas avaliativos que torna permissiva a identificação das dificuldades de se estabelecer a melhoria continua do sistema. Para eles, é a avaliação dos materias de aprendizagem, a avaliação da infraestrutura tecnológica e a avaliação institucional propriamente dita que podem garantir uma sistematização mais apurada e objetiva do sistema avaliativo, possibilitando, desta maneira, o tratamento de pontos específicos que possam se constituir como um entrave ao próprio sistema.

A este respeito, Felix et al. (2017) alertam para o fato de que as avaliações institucionais podem estar a serviço de outros papeis, tais como, garantir o poder e o controle do Estado. Isto porque ao estabelecer uma relação entre os instrumentos utilizados no SINAES e a experiência empregada em nível internacional, Felix et al. (2017), identificaram que o desafio brasileiro é também o desafio europeu.

O desafio apresentado, se estabelece na possível perda da autonomia acadêmica, alinhada ao imperativo governamental que, por sua vez, faz com que o próprio sistema reverbere seus desafios iniciais de maneira sempre latente. Este desafio tão antigo é, ao mesmo tempo atual, como se confirmam com Bettencourt e Maria (2017), que ao refletirem sobre os Sistemas de Avaliação Institucional, evocaram o ponto de vista dos estudantes sobre a mesma, por meio de uma pesquisa em dez instituições do ensino superior para concluir que, apesar de existir uma forte crença de que as avalições podem trazer um resultado positivo, essas ainda são fragilizadas pela ausência de participação dos estudantes em sua elaboração, bem como, na discussão de seus resultados.

Transformando todo o dito em um tecido orgânico e, ao mesmo tempo, dando especificidade ao propósito deste trabalho, considerou-se que a avaliação institucional é aquela voltada para a obtenção de informações que subsidiem a mensuração da qualidade do ensino, 
nas instituições educacionais, bem como aquela capaz de promover mudanças qualitativas a partir de seus resultados.

Em decorrência disso, ao direcionar todo o pensar para o objeto deste estudo, ou seja, o SAI do Centro Paula Souza, aqui retorna para evidenciar o que vem se produzindo na literatura acerca deste assunto. Assim, revisam-se os trabalhos de Souza (2007); Silva (2008); Froncillo (2009); Jacobovicz (2010); Borda (2010); Broti (2012) e Perez (2014), que nos auxiliaram a ampliar o entendimento quanto ao Centro Paula Souza.

Souza (2007) ao realizar um estudo sobre a Avaliação Institucional na Escola Técnica Paulo Guerreiro Franco de Vera Cruz, em São Paulo/SP, buscou identificar as percepções da comunidade escolar sobre um sistema de avaliação implementado em 1999. Ao mesmo tempo, tentou visualizar os reflexos desta avaliação no cotidiano escolar, no que tange à melhoria da qualidade de ensino. Já Silva (2008), buscou definir certo grau de desempenho considerado como ideal para as Escolas Técnicas Estaduais e compará-lo com o nível de desempenho real das respectivas instituições.

No nível técnico, Carvalho (2014, p. 28) voltou seu estudo para a formação técnica a fim de estabelecer uma relação de como os componentes curriculares do atual curso em química do Centro Paula Souza podem preparar os profissionais de nível técnico para as agroindústrias da região administrativa de Barretos.

Neste estudo o autor concluiu que o ensino técnico de nível médio, ao ser pensado exclusivamente como meio de preparo de mão de obra qualificada para inserção no mercado de trabalho, deveria repensar o currículo a fim de atender às novas formas do trabalho de modo a adequar-se a situações concretas.

Na mesma esteira, Jacobovicz, (2010, p. 7), procurou compreender as relações entre a avaliação institucional e os cursos superiores, expondo aspectos que apontem a pertinência dos atuais mecanismos oficiais de avaliação dessa modalidade de ensino.

O entendimento sobre as discussões já realizadas sobre o sistema de avaliação do Centro Paula Souza, quando realiza uma análise a partir da relação entre políticas públicas para a educação e o contexto social, econômico e político em que estão inseridas, Borda (2010), identifica a imanência da necessidade de se disponibilizar informações relativas ao desempenho das escolas. A partir desse cenário, Borda (2010), ao realizar um estudo na Escola Técnica Estadual Professor Pedro Leme Brisolla Sobrinho, apontou os reflexos do SAI de acordo com o próprio cotidiano da escola.

Motivada pelas verificações deste cotidiano, Perez (2014) iniciou pesquisas sobre a meta-avaliação no Centro Paula Souza, observou o processo desenvolvido pelo grupo de 
trabalho do Sistema de Avaliação Institucional da Escola Técnica Estadual Parque da Juventude, notadamente no que se refere aos resultados obtidos e às melhorias que foram desenvolvidas junto aos docentes, discentes, pais e comunidade. Perez (2014) deu enfoque, de forma mais específica, ao SAI do Centro Estadual de Educação Tecnológica Paula Souza (CEETEPS) e direcionou a pesquisa para as concepções, práticas e perspectivas da Avaliação da Escola Técnica Estadual Parque da Juventude.

Todo o dito evidencia que o entendimento dos gestores sobre o SAI ainda não foi explorado. Por esta razão, há que elucidar o que os mesmos entendem a este respeito. Para tanto, buscou-se realizar uma pesquisa empírica cuja metodologia se apresenta a seguir.

\section{Metodologia}

Esta pesquisa é de cunho exploratório e caráter indutivo considerada, por isso mesmo, adequada ao tratamento qualitativo das informações coletadas para o estudo. Para as referidas coletas, a análise documental, a observação participante e o grupo de foco se firmaram como técnicas de pesquisa. A utilização dessas três técnicas permitiu a triangulação de dados, necessária para a realização de pesquisas de cunho qualitativo, como proposto por Richardson (1989).

A presente pesquisa não se detém a sequências rígidas de passos, mas também não se exime de uma revisão aprofundada da literatura que sustenta seu tema, uma vez que o processo de desenvolvimento de um estudo ocorre naturalmente diante dos questionamentos que surgem (RICHARDSON, 1989, p. 131). Além disso, como afirma Merriam (1998), um dos principais meios para coletar dados em pesquisa qualitativa é a observação, por possibilitar os primeiros relatos da situação estudada.

Para a realização deste trabalho, optou-se por este método como forma de realização de um exame minucioso, ou seja, um olhar atento sobre um fenômeno no seu todo ou em algumas partes. No caso em questão, a acessibilidade e a disponibilidade da avaliação institucional do Centro Paula Souza, por meio do SAI. Desta forma, este estudo amparado nas afirmações de Richardson (1989) e Merriam (1998), analisou os seguintes documentos: a) os relatórios do SAI, de 2008 a 2015; b) o Regimento Comum das Etecs; c) os Manuais do SAI; d) o Relatório das Bases de Conhecimentos excertos das questões postadas no Help Desk; e) o Registro da Auto Avaliação do SAI. Além desses documentos formais que dizem respeito ao Centro Paula Souza e ao SAI, os dados coletados por meio do grupo focal também se constituíram em documentos, constituindo-se em objeto de análise documental. Como meio de delineamento e 
sistematização dos trabalhos desenvolvidos, o grupo de foco foi realizado e, aqui, ampara metodologicamente toda discussão resultante do presente trabalho.

Os documentos acima explicitados e o grupo focal triangularam as informações que à luz da fundamentação teórica, puderam ser analisadas e discutidas. Ressalta-se que o grupo de foco é uma técnica de coleta de dados que visa buscar características acerca de determinado assunto, entrevistando vários sujeitos ao mesmo tempo, o que permite, por meio da interação, coletar dados que vão além das simples descrições e/ou opiniões sobre um tema. De acordo com Gatti (2005), o grupo de foco deve ser formado com o consentimento dos participantes, os quais devem possuir algo em comum que garanta certa homogeneidade ao grupo, mas que ao mesmo tempo permita desvelar divergências dentro do mesmo.

Frente ao protocolo a ser seguido no grupo de foco, como método de pesquisa, tornouse necessária a definição dos sujeitos sociais desta pesquisa, para posterior e melhor entendimento de como as informações seriam coletadas. Assim, optou-se por convidar para a realização do grupo de foco os gestores do SAI do Centro Paula Souza. Esses sujeitos sociais foram identificados no universo único da Área de Avaliação Institucional, localizada no Departamento de Desenvolvimento e Planejamento do referido Centro. Esta escolha se deu a partir do entendimento de que os gestores do SAI estão intimamente ligados ao objeto da pesquisa e, por este motivo, constituem-se em potenciais respondentes por excelência.

Uma vez que a equipe de gestores do SAI da unidade analisada é composta por cinco sujeitos, este universo finito se revelou como censitário, e não como uma amostra característica das pesquisas qualitativas. Entretanto, há que se lembrar com Silveira et al. (2004), que é de fundamental importância a definição correta da população a ser pesquisada, em função dos objetivos da pesquisa e do papel do pesquisador.

Definidos os respondentes, um contato pessoal foi realizado com a Coordenadora da Área de Avaliação Institucional do Centro Paula Souza. Para a condução do grupo focal, os gestores do SAI responderam a um roteiro, elaborado como um Protocolo, amparado por Gatti (2005). Este Protocolo foi dividido em quatro etapas: Introdução; Desenvolvimento, Conclusão e Encerramento, aqui apresentados pelas seguintes etapas:

Etapa 1 - Introdução: Nesta etapa foram realizadas as apresentações formais de todos os sujeitos presentes. Foram também coletados os dados de caracterização dos sujeitos sociais. Igualmente, foi solicitado o consentimento de todos para a realização de vídeo gravações, com a assinatura de um Termo de Consentimento Livre e Esclarecido. 
Etapa 2 - Desenvolvimento: Iniciada a etapa de desenvolvimento, foi esclarecido que o tempo previsto para o grupo de foco, inclusive o tempo de duração de discussão de cada questão proposta para o grupo.

Etapa 3 - Conclusão: Ao término da discussão das questões do roteiro, foi apresentado um resumo sobre o que foi mais significativo nas discussões do grupo de foco, a fim de demonstrar a importância e a veracidade dos fatos, relatos, e opiniões coletados para a realização deste estudo.

Etapa 4 - Encerramento: Nesta etapa foram feitos os agradecimentos, principalmente tendo em vista a receptividade destes gestores, que desde as primeiras aproximações foram prestativos em atender com a maior presteza as solicitações de agendamento de reuniões. Após o cumprimento das etapas acima explicitadas, pode-se encaminhar este trabalho para a análise e discussão dos resultados apresentados a seguir.

\section{Análise e discussão dos resultados}

Os dados foram analisados de forma descritiva e interpretativa, segundo paradigmas definidos em pesquisa qualitativa. Inicialmente, os participantes do grupo de foco, por solicitação dos pesquisadores, apresentaram-se formalmente, para que pudessem constar dos registros realizados por meio de vídeo e gravações (GATTI, 2005). No que tange à identificação dos participantes, observou-se que os respondentes possuem bastante experiência dentro do CEETEPS:

\footnotetext{
R1: [...] minha formação é em sociologia, trabalho no CEETEPS há 22 anos, iniciei trabalhando com pesquisa de egressos e, também, trabalhei com planejamento estratégico e depois passou a trabalhar com avaliação institucional há 16 anos.

R2: [...] minha formação é em psicologia, no CEETEPS há 22 anos indo para 23, iniciei trabalhando em $R H$, na área de treinamento, depois fui para a coordenadoria do ensino técnico onde iniciamos os estudos sobre AI.

R3: [...] minha formação é em pedagogia e estou no CPS há cinco anos, primeiro fui para a coordenadoria de ensino técnico, porque meu concurso foi de planejamento educacional, para a área de supervisão.

R4: [...] minha formação é em direito, está no Centro Paula Souza há quatro meses, estou em treinamento, e hoje faço, junto a equipe, o trabalho de apoio administrativo, entre outras coisas acompanho as questões postadas no Help Desk, do SAI.

R5: [...] eu sou Bacharel em Matemática, eu sou MBA em TI, estou há 33 anos na área de TI, comecei como programador, analista de sistema, depois me tornei consultor em TI. Trabalho para a FIPE.
}

O grupo se apresentou com formação heterogênea e também com uma larga experiência no SAI. A este grupo, a primeira questão lançada foi sobre a disponibilidade e a acessibilidade e seu entendimento. Verificou-se que o SAI é para os seus gestores, um trabalho que gera orgulho e que seus resultados são, ao mesmo tempo, importantes para aqueles que o realizam e para aqueles que decidem, a partir da realização do mesmo. Afinal, a "gente" é termo recorrente 
em toda a fala dos participantes como se os mesmos percebessem e encarassem o SAI como um grupo de trabalho, cujo resultado afeta a todos.

Ao mesmo tempo, porém, todos os participantes afirmaram que o SAI está tão disponível quanto acessível para as unidades do Centro Paula Souza, principalmente para a Etecs. No entanto, procura-se entender quem é a Etec, não em suas vias de direito, mas de fato. Afinal, estar disponível não implica, necessariamente, estar acessível como foi visto na fundamentação deste trabalho.

Igualmente, os respondentes destacaram que, mesmo quando os relatórios do sistema eram impressos, orientavam as Etecs que deixassem uma cópia na biblioteca das escolas. A diferença é que, a partir de 2013, por estar disponível em meio eletrônico, na internet, deve-se ter mais cuidados quanto ao acesso, uma vez que é possível obter relatórios mais elaborados. Este fato nos leva ao entendimento de que sempre esteve disponível e acessível às informações que os gestores, de uma maneira geral, permitiram assim estar.

Vale ressaltar que segundo os participantes do grupo de foco, a ampliação ao acesso ao SAI aumentou gradativamente de acordo com as melhorias que se pretendiam ser alcançadas no ensino e seus resultados serviram para a melhoria do próprio sistema. Observou-se também nas discussões do grupo de foco, a frequência dos termos disponibilidade e acessibilidade, embora esses não tenham sido encontrados especificamente nos documentos analisados.

Com relação à identificação das necessidades para aumentar a disponibilidade e a acessibilidade dos resultados da avaliação institucional anualmente, os participantes se manifestaram espontaneamente, inclusive indicando um dos colegas para falar sobre suas experiências.

Esta questão foi direcionada ao respondente responsável pelo Help Desk, indicando que a disponibilidade e a acessibilidade estão intimamente ligadas às dúvidas oriundas da utilização do sistema. Isto não significa necessariamente uma intenção de promover maior clareza e transparência à comunidade acadêmica, uma vez que os usuários do Help Desk são na verdade, em sua maioria, gestores que por algum motivo tiveram alguma dificuldade em seguir as rotas de acesso do SAI. Observe-se, neste quesito, a fala do responsável pelo Help Desk:

R4: [...] o Help Desk, qualquer um que estiver participando, o aluno, o professor toda a comunidade escolar, ela acessa o Help Desk, coloca a dúvida dele e o que ele quer resolver, por quê? Porque ali está registrado e nós vamos responder com registro, claro, que a gente atende ainda por telefone, a gente atende por e-mail independente do Help Desk, mas a gente está colocando o Help Desk para que? Para a gente se policiar, para só responder pelo Help Desk por que é um histórico para a gente, como a gente vai melhorar, como a gente vai fazer no próximo ano [...]”." 
A rigor, percebe-se que o trabalho de esclarecimento de dúvidas da comunidade acadêmica serve de base para a melhoria do próprio sistema de avaliação, mas indica também que não se configura como propósito de amplitude no que tange à disponibilidade e à acessibilidade das informações contidas no SAI. Isto porque os registros constantes no Help Desk não se transformam em bases de entendimento comum, ao passo que as dúvidas oriundas da comunidade acadêmica, bem como as soluções apresentadas, restringem-se aos gestores do sistema. Logo, fica claro que todos corroboraram com a ideia de que implementar uma ferramenta de Help Desk no sistema para registrarem as solicitações, dúvidas e sugestões dos usuários do SAI é fundamental, mas, fica claro também que o público alvo de sua utilização é desconsiderado no que tange a acessibilidade e a disponibilidade da referida informação.

Quanto à disponibilidade, entendida como sendo uma medida da prontidão do sistema, observou-se no sistema Web SAI que esse atende ao especificado pelo autor, quanto às características apresentadas no software em seu funcionamento, por meio da internet. Entretanto, da análise das respostas do grupo de foco e da análise documental, a disponibilidade ainda consiste em termos associados muito mais aos comportamentos dos gestores do SAI do que tecnicamente. $\mathrm{O}$ mesmo acontece com a acessibilidade do SAI.

Assim que os participantes do grupo de foco acreditaram ter respondido ao questionamento, foi apresentada a questão que tratou de como os resultados do SAI são divulgados no Centro Paula Souza e, principalmente, nas Etecs. Como nas questões anteriores, logo um deles se adiantou ao iniciar o relato. O respondente $\mathrm{R} 2$ informou que:

R2: “A orientação que a gente sempre passou é que as unidades escolares divulgassem seus resultados a toda a comunidade, então aos alunos, aos docentes, aos pais, que todas as comunidades participantes da pesquisa, isto historicamente a gente sempre colocou que é uma função da direção da escola divulgar estes resultados, ponto".

Ao alegar à direção a responsabilidade da disseminação das informações do SAI, permitiu-se que as questões relacionadas à disponibilidade e à acessibilidade deixassem de existir, também de ser uma questão de qualidade do SAI para se tornar uma decisão pessoal de diretores de unidades. Mesmo porque, conforme relata o mesmo respondente: "O que está acessivel para eles [a direção], o aluno não tem". E admite: "Hoje ele (aluno) não consegue entrar com o login e ter o acesso a estes resultados (da avaliação institucional promovida pelo SAI)".

O especialista em sistema se manifestou explicando como o sistema se encontra estruturado, no momento. Apesar de informar que do ponto de vista técnico. o WebSAI no momento da avaliação institucional está disponível e acessível quase $100 \%$ do tempo, sete dias 
por semana, 24 horas por dia, e se procura incessantemente torná-lo mais simples possível para que as pessoas possam executar esta tarefa e participar do WebSAI num menor tempo possível para não comprometer aula, não comprometer as atividades da educação. Novamente evidencia-se o entendimento de que as pessoas podem executar esta tarefa, tanto no que se refere à alimentação do sistema quanto aos dados considerados básicos para a avaliação institucional. Não se trata necessariamente do fato de que o SAI está disponível e acessível ao longo do tempo para que seja utilizado como fonte de consulta sobre a avaliação institucional, ou seja, o resultado da avaliação realizada pelo SAI.

Com relação às ações futuras, o grupo de foco continuou a discussão e passou a relatar como são previstas as ações necessárias para aumentar a disponibilidade e a acessibilidade dos resultados da avaliação institucional. A intenção é realizar uma leitura mais precisa e mais alinhada aos indicadores direcionados à gestão educacional de cada unidade, conforme relatou o respondente 03, no exercício de seu papel, enquanto gestor. Afinal, desenvolver suas atividades a partir do entendimento sobre "[...] qual o conjunto de ações? Ou, [...] o que vou fazer para melhorar a minha Unidade?" São questões que, segundo o mesmo respondente, "[...] transcende um pouco a questão da avaliação institucional, vinculando-se, diretamente, às ações futuras". Para os participantes, as ações futuras se relacionam aos seus trabalhos, ou seja, com as suas atividades. A rigor, a disponibilidade e a acessibilidade das informações se relacionaram às ações futuras para a melhoria destes atributos de qualidade para a gestão do SAI, e não propriamente para a comunidade acadêmica. Tanto é fato, que o respondente 03 afirma que:

Respondente 03: [...] "por meio do SAI, estamos medindo bem a qualidade da educação e do ensino no Centro Paula Souza, e que uma ação futura deve estar direcionada à visualização [...] dos desdobramentos, [ou seja, sobre] quais são os planos de ação que têm que ser realizados igualmente nas unidades, para alinhar mais adequadamente os indicadores, para que a próxima medição seja ainda melhor, e possa monitorar esses planos".

Complementado pelo respondente 04: "Pensamento este que é realizado e direcionado apenas à gestão já que ele "[...] é feito pela Supervisão, e chegaria até o Coordenador de Curso”.

Quando tratada à luz do objeto deste trabalho, ou seja, da disponibilidade e da acessibilidade, a fim de verificar como é realizada a autoavaliação do SAI, percebeu-se que a mesma se encontra no cerne da Visão e da Missão do Centro Paula Souza. Por sua vez, esta fundamenta os princípios para a elaboração do sistema avaliativo. Apesar de tal objetivo estar delineado com muita clareza nos documentos analisados que tratam da fundamentação teórica e metodológica do SAI, os gestores ainda se deparam com questões estruturais referentes à conexão com a internet e a falta de equipamentos adequados para participar do processo de 
avaliação. Assim, apesar da melhoria contínua no sistema avaliativo, esse ainda está longe da linha da excelência.

Segundo os gestores, para minimizar esta distância é preciso um conjunto de outras ações que independem dos gestores do sistema. Destacam que para se concretizar qualquer tipo de avaliação, há necessidade de investimento contínuo por parte do próprio Centro Paula Souza, apesar de que foram feitos investimentos quanto à infraestrutura criada para manter o SAI em funcionamento ao longo do tempo. Os resultados e a análise ora apresentados permitiram tecer algumas considerações de ordem final neste trabalho.

\section{Considerações finais}

Ficou claro, pelos resultados alcançados, que o gestor do SAI é, na verdade, um avaliador no processo de avaliação. Neste sentido, a afirmação de Perez (2014) sobre a participação dos gestores no processo de meta-avaliação do Centro Paula Souza se mostra como fato, também, no presente estudo. Entretanto, há centralidade das informações que são importantes e necessárias em cada nível de ações, mostrando que a disponibilidade e a acessibilidade são quesitos, na verdade, necessários somente a quem a própria gestão julga interessar, corroborando com os dizeres de Borda (2010), quando afirma a necessidade de se disponibilizar informações relativas ao desempenho das escolas.

Sabe-se que as atribuições legais fornecidas pelos documentos institucionais delegam ao diretor de cada unidade a decisão sobre como disseminar - se assim desejar, os resultados da avaliação institucional, anualmente, em sua unidade. Entretanto, isto é sugerido, não obrigatório. Por isso mesmo, a decisão de se participar a comunidade sobre os resultados do SAI é uma decisão que vai para além da compreensão das simples relações institucionais, já que, como bem alerta Belloni (1969), o principal objetivo da avaliação institucional é criar métricas capazes de se atingir os resultados esperados a partir dos fatores sócios econômicos, políticos e culturais, nas quais as instituições se inserem avaliando.

Ainda a este respeito, os resultados anuais sobre a avaliação institucional realizada pelo SAI, no Centro Paula Souza não estão, na realidade, disponíveis e acessíveis à comunidade acadêmica, aos pais de alunos e aos egressos. Por esta razão, a representação de todos os segmentos no processo de elaboração do sistema auto avaliativo apresentou-se comprometida, apontando para a ausência do que Andriola e Souza (2010) consideram condição sine qua non nos processos avaliativos: a representatividade dos agentes envolvidos direta e indiretamente na composição da vida escolar. Ao mesmo tempo, há vestígios de que a ideia de melhoria das 
ações e, até mesmo, do sistema avaliativo é hierarquicamente institucionalizada, desvelando o pressuposto de que, como bem afirma Felix et al. (2017), as avaliações institucionais estejam a serviço de outros papeis, tais como, garantir o poder e o controle do Estado.

Importa ressaltar que a gestão participativa ou a gestão democrática preconizada pelos Conselhos Estaduais de Educação não se faz presente no que tange aos mecanismos que se alinham e se desdobram do SAI. Esta é ainda, uma dificuldade presente já evidenciada em 2005 por Dias Sobrinho (2005).

Dando especificidade à disponibilidade e à acessibilidade, tornou-se possível o entendimento de que a avaliação está sob a égide política, acadêmica e administrativa conforme Ristoff (1995), e, por isso, perpetua-se a crença de que a comunidade externa não deve participar de sua elaboração e, principalmente, da discussão de seus resultados como afirma Bettencourt e Maria (2017) na conclusão de seus trabalhos sobre o tema. Foi o que se pode entender, por meio da análise das respostas do grupo de foco.

A pesquisa permitiu concluir também que há evidências de entendimento dos gestores sobre o assunto e os termos: disponibilidade e acessibilidade. Mas são ainda tímidas ou inexistentes as ações previstas para aumentar a disponibilidade e a acessibilidade dos resultados da avaliação institucional realizada pelo SAI para a comunidade acadêmica do Centro Paula Souza, especialmente para as Etecs. Logo, a necessidade apontada por Ashley et al. (2006), para quem as referidas comissões podem e devem incorporar novos parâmetros ao sistema que sejam convergentes às necessidades de cada instituição, considerando, ainda, que a comunidade acadêmica se arma e se mostra ainda fragilizada, já que um sistema de avaliação institucional deve prever em seu desenvolvimento o acesso aos usuários, isto é, à comunidade, além dos gestores. Para tanto, desde o início de sua definição e construção até os aspectos de confiabilidade.

Em vias de conclusão acerca deste item é importante salientar que não há registro de nenhum dos dois atributos de qualidade dos sistemas de informação, disponibilidade e acessibilidade em documentos que formalizem os atos legais da Instituição. Em decorrência disso, recomenda-se com Silva e Gomes (2011), o delineamento de uma cultura de avaliação por meio da busca sistematizada pela melhoria contínua das instituições, melhoria esta que pode ser exitosa na consideração da comunidade externa na elaboração, discussão e avaliação dos isntrumentos avaliativos. Cabe destacar, entretanto, a disposição dos gestores do SAI em tornar o sistema cada dia melhor e que, não poupam esforços nesse sentido.

No entanto, transparece que a transformação de suas intenções em ações concretas com relação à disponibilidade e à acessibilidade no que tange aos resultados da avaliação 
institucional realizada pelo SAI não depende de suas vontades. O que não implica, necessariamente, no que se pode ou não fazer. Segundo o entendimento dos gestores, deverá haver uma vontade política para que haja transformações concretas, a fim de alcançar a disponibilidade e a acessibilidade do SAI em termos de resultados da avaliação institucional para a comunidade acadêmica. Ou seja, a disponibilidade e a acessibilidade ao SAI, no seu todo.

Questões como lentidão do sistema, dificuldade de acesso, infraestrutura, preenchimento dos formulários, bem como a vontade de participação (ou a falta dela) por parte de algumas equipes, e, até mesmo de unidades, permearam nas falas dos respondentes. A dificuldade de se realizar este trabalho, no processo avaliativo, também.

Verificou-se que todas as questões postas e fundamentadas na literatura, ao que se refere ao sistema de avaliação institucional também se firmam como desafios a serem superados no SAI. Neste sentido, a qualidade, a acreditação e a garantia da qualidade ainda são entraves que devem ser considerados na elaboração e no desenvolvimento do sistema de avaliação. Ao que parece, esta pesquisa lança mais um desafio, ao mesmo tempo no qual, evoca uma necessidade a ser superada: a de se (re)pensar o acesso e a disponibilidade dos resultados dos sistemas de avaliação como meio de encorajamento e incentivo à participação da comunidade acadêmica, de pais e de egressos.

Como todo trabalho realizado, a conclusão não se firma necessariamente como um fechamento, mas como possibilidades de desenvolvimento de novos olhares e de novas questões que permitam o desvendamento de situações cotidianas. Para tanto, frente ao cumprimento do objetivo proposto, ficam sugestões para pesquisas futuras no sentido de aprofundar estudos sobre o SAI do Centro Paula Souza, vislumbrando atributos e critérios que interferem na qualidade de sistemas de informação como: efetividade, eficiência, integridade, confiabilidade, confidencialidade, conformidade, usabilidade, entre outros. Também a replicação da mesma sob outros protocolos metodológicos, tais como, a análise quantitativa. A ampliação desta pesquisa em sistemas de avaliação institucional em outras universidades brasileiras ainda poderá ser considerada. O tema é instigante e inovador.

\section{Referências}

ANDRIOLA, Wagner Bandeira; SOUZA, Laura Alves de. Representações sociais dos gestores e dos técnicos das unidades acadêmicas da Universidade Federal do Ceará (UFC) acerca do auto avaliação institucional. Avaliação, Campinas; Sorocaba, v. 15, n. 2, p. 45-72, jul. 2010. Disponível em: http://www.scielo.br/pdf/aval/v15n2/a03v15n2.pdf. Acesso em: 25 mar. 2020. 
ASHLEY, Patrícia Almeida et al. Sistema Nacional de Avaliação da Educação Superior: oportunidades para a responsabilidade social na gestão estratégica de instituições de ensino superior. Revista Ibero-Americana de Estratégia, São Paulo, v. 5, n. 1, 2006.

BELLONI, Isaura. Avaliação Institucional: um instrumento de democratização da educação. Linhas Críticas, Salvador, v. 5, n. 9, p, 31-58, 1969. Disponível em: https://www.mendeley.com/catalogue/dcf6293b-1568-36d2-a575-36c08f0ef440/. Acesso em: 1 mar. 2014.

BETTENCOURT, Maria Beatriz; MARIA, de Lourdes. Significados das avaliações do ensino pelos estudantes: um estudo qualitativo na educação superior brasileira. Revista Lusófona de Educação, Lisbon, v. 36, n. 36, 2017.

BORDA, Viviane. Avaliação institucional nas escolas técnicas do Centro Paula Souza: o observatório escolar. 2010. Dissertação (Mestrado) - Universidade Estadual de São Paulo, Marília, 2010. Disponível em: https://www.marilia.unesp.br/Home/Posgraduacao/Educacao/Dissertacoes/borda_v_me_mar.pdf. Acesso em: 1 mar. 2014.

BRASIL. Portaria no 1.140 de 22 de novembro de 2013. Seção que pactua a Educação como direito de todos. Capítulo III da Educação, da Cultura e do Desporto. Seção Ida Educação. Disponível em:

http://pactoensinomedio.mec.gov.br/images/pdf/constituicao_educacao.pdf. Acesso em: 2 nov. 2015.

BRASIL. Decreto $n^{0} 5.296$ de 2 de dezembro de 2004. Disponível em:

http://www.planalto.gov.br/ccivil_03/_Ato2004-2006/2004/Decreto/D5296.htm. Acesso em: 13 maio 2014.

BROTI, Marcelo Peralli. O ensino superior no Centro Estadual de Educação Tecnológica Paula Souza: sujeitos, experiências e currículo (1969-1976). 2012. 97 f. Dissertação (Mestrado em Educação) - Pontifícia Universidade Católica de São Paulo, São Paulo, 2012. Disponível em: https://tede2.pucsp.br/handle/handle/10369?mode=full. Acesso em: 01 mar. 2014.

CARVALHO, Ronaldo Pedrosa de. Formação Técnica de Nível Médio em Química do Centro Paula Souza e sua relação com o perfil industrial da Região Administrativa de Barretos. Dissertação (Mestrado) - Universidade Federal de São Carlos, São Carlos, 2014. Disponível em: www.bdtd.ufscar.br/htdocs/tedeSimplificado//tde busca/arquivo.php. Acesso em: 1 mar. 2014.

CEETEPS. Deliberação CEETEPS N 003, de 18-7-2013. Regimento Comum das Escolas Técnicas Estaduais do Centro "Paula Souza". D. O.E. Poder Executivo - Seção I, p. 123. São Paulo, 2013.

CEETEPS. Perfil e histórico. Disponível em: http://www.cps.sp.gov.br/quem-somos/perfilhistorico/ . Acesso em: 3 set. 2015.

COSTA, Eula Maria de Melo Barcelos; BARA, Maria Teresa Freitas; GARCIA, Telma Alves. Momentos de avaliação e movimentos de mudança em um curso de Farmácia. Avaliação, Campinas; Sorocaba, v. 18, n. 3, p. 613-628, nov. 2013. Disponível em: 
http://www.scielo.br/scielo.php?script=sci_arttext\&pid=S1414-40772013000300006. Acesso em: 25 mar. 2018.

DIAS SOBRINHO, José. Educação superior, globalização e democratização: qual universidade? Rev. Bras. Educ., Rio de Janeiro, n. 28, p. 164-173, abr. 2005.

FELIX, Glades Tereza et al. Avaliação da educação superior: um comparativo dos instrumentos de regulação entre Brasil e Portugal. Avaliação, Campinas; Sorocaba, v. 22, n. 1, p. 35-54, jun. 2017. Disponível em: http://www.scielo.br/pdf/aval/v22n1/1982-5765-aval22-01-00035.pdf . Acesso em: 25 mar. 2018.

FREITAS, Iêda Maria C.; SILVEIRA, Amélia. Avaliação da educação superior. Florianópolis: Insular, 1997.

FRONCILLO, Roberta. Sistema de avaliação institucional: práticas e desafios. Edição comemorativa 40 anos do Centro Paula Souza. São Paulo: Centro Paula Souza, 2009.

GATTI, Bernadette A. Grupo focal na pesquisa em ciências sociais e humanas. Brasília: Liber Livro, 2005.

GUBA, Egon G. ; LINCOLN, Yvonna S. Competing paradigms in qualitative research. In: DENZIN, N. K.; LINCOLN, Y.S. (eds.). Handbook of qualitative research. Thousand Oaks, CA: Sage, 1994. p. 105-117.

HENRY, Shawn Lawton. Introduction to web accessibility. 2005. Disponível em: http://www.w3.org/WAI/intro/accessibility.php. Acesso em: 6 fev. 2015.

JACOBOVICZ, Márcia Maria Vasquez Thomé. Avaliação institucional dos cursos superiores de tecnologia no Brasil. 2010. Dissertação (Mestrado) - Centro Paula Souza, São Paulo, 2010. Disponível em:

http://www.centropaulasouza.sp.gov.br/Posgraduacao/Trabalhos/Dissertacoes/formacaotecnologica/2011/marcia-maria-vasquez-thome-jacobovicz.pdf. Acesso em: 13 fev. 2014.

LEPORINI, Bárbara; PATERNÒ, Fábio. Increasing usability when interacting through screen readers. Universal Access in the Information Society, Heidelberg, v. 3, n. 1, p. 57-70, 2004.

LIMA, Cláudia Regina Uchôa de. Acessibilidade tecnológica e pedagógica na apropriação das tecnologias de informação e comunicação por pessoas com necessidades educacionais especiais. Dissertação (Mestrado) - UFRG, Porto Alegre. 2003. Disponível em: http://www.lume.ufrgs.br/bitstream/handle/10183/3709/000391527.pdf?sequence=1. Acesso em: 30 mar. 2014.

MERRIAM, Sharan B. Qualitative research and case study applications in education. 2. ed. San Francisco, CA: Jossey-Bass, 1998.

N'DONGA, João Zolá. Gestão de manutenção orientada à confiabilidade de componentes de aviação da força aérea de nacional de angola (FANA). Dissertação (Mestrado) Instituto Militar de Engenharia, Rio de Janeiro, 2010. 
PAULA FILHO, Carlos Botelho de. Estratégia de web cache utilizando redes P2P de clientes sobre WebRTC. 2016. Dissertação (Mestrado em Informática) - Universidade de Brasília, Brasília, 2016.

PEREZ, Marinês Oliveira. Meta-avaliação do sistema de avaliação institucional da escola técnica estadual parque da juventude do Centro Paula Souza. 2014. 147 f. Dissertação (Mestrado em Educação) - Universidade Nove de Julho, São Paulo, 2014.

PIEDADE, Ana Maristela Opoloski. Análise da acessibilidade comunicacional nos websites dos institutos federais brasileiros. Dissertação (Mestrado) - Universidade Regional de Blumenau, Blumenau, 2016. Disponível em:

http://www.bc.furb.br/docs/DS/2016/361134_1_1.pdf. Acesso em: 5 fev. 2018

RICHARDSON, Roberto Jarry. Pesquisa social: métodos e técnicas. São Paulo: Atlas, 1989.

RISTOFF, Dilvo I. Avaliação institucional: pensando princípios. In: BALZAN, Cesar Newton; DIAS SOBRINHO, José (orgs.). Avaliação institucional: teoria e experiências. Cortez, 1995. p. 37-85

SILVA, Marta Leandro da. A avaliação institucional das escolas técnicas do Centro Estadual de Educação Tecnológica Paula Souza. 2008. 318 f. Tese (Doutorado em Ciências Humanas) - Universidade Federal de São Carlos, São Carlos, 2008. Disponível em: https://repositorio.ufscar.br/handle/ufscar/2201. Acesso em: 2.jun. 2014.

SILVA, Assis Leão da; GOMES, Alfredo Macedo. Avaliação institucional no contexto do SINAES: a CPA em questão. Avaliação, Campinas; Sorocaba, v. 16, n. 3, p. 573-601, nov. 2011. Disponível em: http://www.scielo.br/pdf/aval/v16n3/v16n1a05 Acesso em: 25 mar. 2018.

SILVEIRA, Amélia et al. (Coord.). Apresentação e editoração de teses, dissertações e monografias. Blumenau: Ed. da FURB, 2004.

SOUZA, Sonia Maria Valsecchi Ribeiro de. Um estudo sobre a avaliação institucional em uma escola técnica estadual paulista. 2007. 120 f. Dissertação (Mestrado) - Faculdade de Filosofia e Ciências, Universidade Estadual Paulista, São Paulo, 2007. Disponível em: http://hdl.handle.net/11449/96388. Acesso em: 12 jan. 2018.

TANAKA, Eduardo Hideki. Método baseado em heurísticas para avaliação de acessibilidade em sistemas de informação. 2009. Tese (Doutorado) - Universidade Estadual de Campinas, Campinas, 2009. Disponível em: http://repositorio.unicamp.br/bitstream/REPOSIP/275827/1/Tanaka_EduardoHideki_D.pdf. Acesso em: 6 fev. 2015.

TERÇARIOL, Adriana Aparecida de Lima et al. As dimensões da avaliação em cursos online: reflexões e importância/Dimensions assessment in online courses: reflections and importance. Revista Iberoamericana de Educación a Distancia, Madrid, v. 19, n. 2, p. 283 $300,2016$. 